\title{
Impact of School Closures due to COVID-19 on Children with Neurodevelopmental Disorders in Japan
}

\author{
Naomi Kawaoka ${ }^{1} \cdot$ Kei Ohashi ${ }^{1}$ (I) Satomi Fukuhara ${ }^{1} \cdot$ Taishi Miyachi $^{1} \cdot$ Tomoko Asai $^{1} \cdot$ Masayuki Imaeda $^{1}$. \\ Shinji Saitoh ${ }^{1}$
}

Accepted: 29 May 2021 / Published online: 3 June 2021

(C) The Author(s), under exclusive licence to Springer Science+Business Media, LLC, part of Springer Nature 2021

\begin{abstract}
In March 2020, many schools were closed to prevent the spread of COVID-19 in Japan, and it is predicted that many children, especially those with neurodevelopmental disorders (NDDs), will be affected emotionally and behaviorally. Here, we examined the impact of school closures due to COVID-19 on school-aged children with NDDs using the Child Behavior Checklist. Totally, data on 121 children diagnosed with autism spectrum disorder, attention-deficit hyperactivity disorder, and/or intellectual disorder were analyzed and it was found that externalizing and aggressive behavior increased in all NDDs, regardless of the type of diagnosis. A clear prospect is important for children with NDDs children to lead a stable life, and more generous supports for children with NDDs and their families are needed.
\end{abstract}

Keywords Attention-deficit hyperactivity disorder · Autism spectrum disorder · COVID-19 · Intellectual disorder . Neurodevelopmental disorder

In December 2019, the world's first case of coronavirus disease 2019 (COVID-19) was confirmed in China, and thereafter spread rapidly on a global scale (Yeasmin et al., 2020). Furthermore, as of December 13, 2020, 70,476,836 people were infected with COVID-19 and 1,599,922 have died. To prevent further spread of the disease, cities were in lockdown and schools were closed; however, the number of infected people continued to increase. In Japan, the first case of COVID-19 was confirmed on January 16, 2020, with 177,287 people infected and 2,562 people having died as of December 13, 2020. Although cities in Japan were not locked down, almost all elementary and junior high schools were closed from the beginning of March 2020 to the end of May 2020 to prevent the spread of the infection, which greatly changed children's living environments.

The lockdown of cities and school closures caused not only traumatic experiences but also changes in the environment, such as experiences of isolation and changes in daily routines. The home confinement of children is associated

Kei Ohashi

k.ohashi@med.nagoya-cu.ac.jp

1 Department of Pediatrics and Neonatology, Graduate School of Medical Sciences, Nagoya City University, 1 Kawasumi, Mizuho-Cho, Mizuho-Ku, Nagoya 467-8601, Japan with uncertainty and anxiety, which is attributable to disruption in their education, physical activities, and opportunities for socialization (Jiao et al., 2020). Sudden changes in an environment can be stressful for anyone; however, it is said that children with neurodevelopmental disorders (NDDs) are more vulnerable to environmental changes and unpredictable situations than children with typical development (Singh et al., 2020). Therefore, it is supposed that the behaviors and emotions of children with NDDs were differentially affected by school closures. Many studies on the impact of the lockdown of cities and school closure due to COVID-19 on children revealed that anxiety and depression increased (Tang et al., 2021; Xie et al., 2020; Yeasmin et al., 2020; Zhou et al., 2020). However, most of these studies have examined only the condition after the closure or have been conducted on children with typical development, and little study has been done for impact of school closures due to COVID-19 on children with NDDs. Studying the impact of school closures due to COVID-19 on children with NDD is important to identify the support needed during other infectious disease outbreaks and disasters.

In this study, we examined the behavioral and emotional changes of children with NDDs before and after school closure to detect the impact and influence of school closures due to COVID-19 on children with NDDs. 


\section{Methods}

\section{Subjects}

We extracted data from 260 school-aged patients from 6 to 14 years old as of 1 April 2020 who visited the Psychology and Development Section in the Department of Pediatrics and Neonatology, Nagoya City University Hospital between 1 April, 2019 and 31 March, 2020. In total, 122 patients were excluded because of no response, 10 patients because of insufficient answers to questions, and 7 patients due to other reasons (6 patients without diagnosis of NDDs, and 1 patient lived in a dormitory). Finally, 121 patients were enrolled to participate in this study (Fig. 1).

\section{Procedure}

A questionnaire about children's living environments and the two Child Behavior Checklists (CBCL), about before and after school closure, were simultaneously mailed to the subjects on 15 May 2020; their parents/guardians completed the form and then returned it to us. The questionnaire about the living environment included items about the type of class the participant belonged to, the number of days they attended school per week, whether the school was closed, and the place they spent their time during school closure. The CBCL is a checklist developed by Achenbach et al. (1991) that assesses the emotional and behavioral problems of children in early childhood and school-age, in which parents responded on a Likert scale with a choice of 0 (not true), 1 (somewhat or sometimes true), or 2 (very true or often true) about their child's present condition compared to six months ago. In this study, the emotional and behavioral problems of participants were evaluated, using the CBCL, two weeks before school closure and in the present two weeks after school closure, respectively. The CBCL scores were converted to T-scores (standard scores) based on the conversion table and statistically tested with EZR statistical software (Saitama Medical Centre, Jichi Medical University; http:// www.jichi.ac.jp/saitama-sct/SaitamaHP.files/statmedEN. html; Kanda, 2013). The internalizing scale and syndrome scale of withdrawal were excluded from the analysis because subjects were forced to withdraw due to COVID-19. We collected diagnostic information according to the Diagnostic and Statistical Manual of Mental Disorders 5th edition

Eligible patients $(n=260)$

School-aged patients who visited the Psychology and Development Section in the Department of Pediatrics and Neonatology, Nagoya City University Hospital between 1 April 2019 and 31 March 2020.

Exclude

Not replied by June 30, $2020(\mathrm{n}=122)$

Replied by June 30, 2020

$(\mathrm{n}=138)$

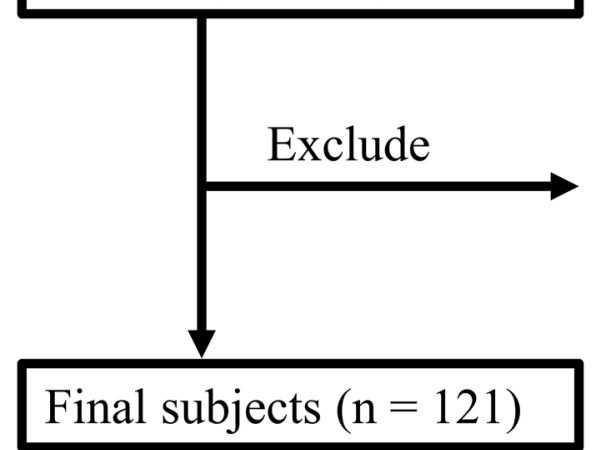

Fig. 1 Selection of subjects 
(American Psychiatric Association 2013) and intelligence quotient (IQ) from participants' medical records. We analyzed the whole sample and sub-groups (ASD, ADHD, and ID) which classified with allowing duplication of patients.

Ethics approval was obtained from the ethics committee of Nagoya City University Medical School (No. 60-200018). The research instructions and consent documents were mailed together; therefore, informed consents were obtained in writing.

\section{Results}

\section{Patients' Profile}

One hundred and twenty-one patients were enrolled in this study and their characteristics are summarized in Table 1. Of these 121 subjects, 84 (69.4\%) were male, with a median age of 11.0 years (IQR: $9.0-13.0)$, and $9(7.4 \%)$ were nonattenders even before school closures. The clinical diagnosis of NDD was as follows (including patients with two or more neurodevelopmental disorders): autism spectrum disorder (ASD) (including suspicion): 88, attention-deficit hyperactivity disorder (ADHD) (including suspicion): 44, and intellectual disorder (ID) (including borderline IQ): 40. Eighty-five patients belonged to regular classes (14 of them used special support services in resource rooms), 28 to special classes for children with special needs, 7 to schools for special needs education, and 1 to a specially designated guidance classroom. While schools were closed, 75 patients stayed only in their homes with 46 also having stayed in places other than their homes (i.e., relative's home: 7, exceptional school attendance: 5, normal after-school daycare: 6, after-school daycare for disabled children: 32, and mother's workplace: 3 ; including multiple answers).

\section{CBCL Score Before and After School Closures}

The median T-scores of the CBCL before and after school closures are shown in Table 2. The total problem scale, externalizing scale, and all syndrome scales before school closures did not differ significantly among all patients and among patients with ASD, ADHD, and ID as indicated by the Kruskal-Wallis test. Furthermore, after school closures, $\mathrm{T}$-scores on the total problem scale, externalizing scale, and each syndrome scale of thought problems, delinquent behavior, and aggressive behavior significantly increased as indicated by Wilcoxon's signed-rank sum test. In the analysis by diagnostic group, patients with ASD had significantly elevated T-scores on the total problem scale, externalizing scale, and each syndrome scale of thought problems and aggressive behavior. Patients with ADHD had significantly

Table 1 Subjects' characteristics

\begin{tabular}{|c|c|c|c|c|}
\hline & All subjects $(\mathrm{n}=121)$ & Subjects with ASD $(\mathrm{n}=88)$ & Subjects with ADHD $(\mathrm{n}=45)$ & Subjects with ID $(n=40)$ \\
\hline Sex & Male 44, Female 37 & Male 63, Female 25 & Male 31, Female 14 & Male 26, Female 14 \\
\hline Age, median (IQR) & $11.0(9.0-13.0)$ & $11.0(9.0-13.0)$ & $11.0(10.0-13.0)$ & $11.0(8.0-12.0)$ \\
\hline \multicolumn{5}{|l|}{ Type of class/school } \\
\hline Regular class & 71 & 52 & 36 & 8 \\
\hline $\begin{array}{l}\text { Special classes for children } \\
\text { with special needs }\end{array}$ & 28 & 20 & 3 & 23 \\
\hline $\begin{array}{l}\text { Specially designated guidance } \\
\text { classroom }\end{array}$ & 1 & 1 & 1 & 0 \\
\hline $\begin{array}{l}\text { Schools for special needs } \\
\text { education }\end{array}$ & 7 & 5 & 0 & 5 \\
\hline Resource room & 14 & 10 & 5 & 4 \\
\hline \multicolumn{5}{|l|}{ Attendance } \\
\hline Truancy & 9 & 8 & 2 & 2 \\
\hline Not truancy & 112 & 80 & 43 & 38 \\
\hline \multicolumn{5}{|l|}{ Place during school closure } \\
\hline Only their home & 75 & 55 & 32 & 19 \\
\hline Not only their home & 46 & 33 & 13 & 21 \\
\hline Relative's home & 7 & 6 & 7 & 2 \\
\hline Exceptional school attendance & 5 & 4 & 0 & 2 \\
\hline Normal after-school daycare & 6 & 6 & 0 & 4 \\
\hline $\begin{array}{l}\text { After-school daycare for disa- } \\
\text { bled children }\end{array}$ & 32 & 24 & 10 & 17 \\
\hline
\end{tabular}

$A S D$ autism spectrum disorder, $A D H D$ attention-deficit hyperactivity disorder, $I D$ intellectual disorder, $I Q R$ interquartile range 
Table 2 T-score of CBCL before and after school closure

\begin{tabular}{|c|c|c|c|c|c|c|c|c|}
\hline & \multicolumn{2}{|c|}{ All subjects $(n=121)$} & \multicolumn{2}{|c|}{ Subjects with ASD $(n=88)$} & \multicolumn{2}{|c|}{$\begin{array}{l}\text { Subjects with ADHD } \\
(\mathrm{n}=45)\end{array}$} & \multicolumn{2}{|c|}{ Subjects with ID $(n=40)$} \\
\hline & Before & After & Before & After & Before & After & Before & After \\
\hline Total problem score & $\begin{array}{l}63 \\
(56-67)\end{array}$ & $\begin{array}{l}63 * * \\
(57-68)\end{array}$ & $\begin{array}{l}62.5 \\
(56-67)\end{array}$ & $\begin{array}{l}63 * * \\
(56-68)\end{array}$ & $\begin{array}{l}65 \\
(59-69)\end{array}$ & $\begin{array}{l}67 * * \\
(62-71)\end{array}$ & $\begin{array}{l}63 \\
(57-64.3)\end{array}$ & $\begin{array}{l}64.5 * * \\
(57.8-66)\end{array}$ \\
\hline Internalizing scale & $\begin{array}{l}58 \\
(52-65)\end{array}$ & $\begin{array}{l}58 \\
(52-64)\end{array}$ & $\begin{array}{l}59 \\
(52-65)\end{array}$ & $\begin{array}{l}59 \\
(52.8-64.3)\end{array}$ & $\begin{array}{l}58.5 \\
(54-67)\end{array}$ & $\begin{array}{l}61 \\
(54-67)\end{array}$ & $\begin{array}{l}54 \\
(49-59)\end{array}$ & $\begin{array}{l}56 \\
(51.3-59.5)\end{array}$ \\
\hline Externalizing scale & $\begin{array}{l}58 \\
(53-66)\end{array}$ & $\begin{array}{l}60 * * \\
(53-66)\end{array}$ & $\begin{array}{l}57.5 \\
(53-64.5)\end{array}$ & $\begin{array}{l}59 * * \\
(53-66)\end{array}$ & $\begin{array}{l}59 \\
(54-69)\end{array}$ & $\begin{array}{l}61 * * \\
(56-70)\end{array}$ & $\begin{array}{l}58 \\
(53-64.3)\end{array}$ & $\begin{array}{l}61^{* *} \\
(53.8-66)\end{array}$ \\
\hline \multicolumn{9}{|l|}{ Syndrome scales } \\
\hline Withdrawn & $\begin{array}{l}59 \\
(53-63)\end{array}$ & $\begin{array}{l}59 \\
(53-65)\end{array}$ & $\begin{array}{l}59 \\
(53-65.3)\end{array}$ & $\begin{array}{l}59 \\
(53-66)\end{array}$ & $\begin{array}{l}61 \\
(53-66)\end{array}$ & $\begin{array}{l}63 \\
(59-67)\end{array}$ & $\begin{array}{l}53 \\
(53-60)\end{array}$ & $\begin{array}{l}59 \\
(53-63)\end{array}$ \\
\hline Somatic complaints & $\begin{array}{l}50 \\
(50-54)\end{array}$ & $\begin{array}{l}50 \\
(50-55)\end{array}$ & $\begin{array}{l}50 \\
(50-54.3)\end{array}$ & $\begin{array}{l}50 \\
(50-55)\end{array}$ & $\begin{array}{l}50 \\
(50-55)\end{array}$ & $\begin{array}{l}50 \\
(50-55)\end{array}$ & $\begin{array}{l}50 \\
(50-50)\end{array}$ & $\begin{array}{l}50 \\
(50-51)\end{array}$ \\
\hline Anxious/depressed & $\begin{array}{l}55 \\
(50-63)\end{array}$ & $\begin{array}{l}55 \\
(50-63)\end{array}$ & $\begin{array}{l}57.5 \\
(50-63.3)\end{array}$ & $\begin{array}{l}58 \\
(51.5-64)\end{array}$ & $\begin{array}{l}58 \\
(50-64)\end{array}$ & $\begin{array}{l}57 \\
(50-67)\end{array}$ & $\begin{array}{l}53 \\
(50-58.5)\end{array}$ & $\begin{array}{l}55^{*} \\
(50-60.3)\end{array}$ \\
\hline Social problems & $\begin{array}{l}63 \\
(57-68)\end{array}$ & $\begin{array}{l}63 \\
(59-68)\end{array}$ & $\begin{array}{l}63 \\
(57-68)\end{array}$ & $\begin{array}{l}63 \\
(58.5-68)\end{array}$ & $\begin{array}{l}63 \\
(59-68)\end{array}$ & $\begin{array}{l}63 \\
(60-68)\end{array}$ & $\begin{array}{l}65 \\
(59-67.3)\end{array}$ & $\begin{array}{l}65 \\
(61.5-68)\end{array}$ \\
\hline Thought problems & $\begin{array}{l}56 \\
(50-69)\end{array}$ & $\begin{array}{l}56^{*} \\
(50-70)\end{array}$ & $\begin{array}{l}56 \\
(50-70)\end{array}$ & $\begin{array}{l}56^{*} \\
(50-70)\end{array}$ & $\begin{array}{l}56 \\
(50-69)\end{array}$ & $\begin{array}{l}56^{*} \\
(50-70)\end{array}$ & $\begin{array}{l}56 \\
(50-70)\end{array}$ & $\begin{array}{l}56 \\
(50-70)\end{array}$ \\
\hline Attention problem & $\begin{array}{l}63 \\
(58-69)\end{array}$ & $\begin{array}{l}65 \\
(59-69)\end{array}$ & $\begin{array}{l}63 \\
(58-68.3)\end{array}$ & $\begin{array}{l}63 \\
(58-69)\end{array}$ & $\begin{array}{l}65 \\
(61-70)\end{array}$ & $\begin{array}{l}67 \\
(61-70)\end{array}$ & $\begin{array}{l}66 \\
(59.8-70)\end{array}$ & $\begin{array}{l}67 \\
(61-70)\end{array}$ \\
\hline Delinquent behavior & $\begin{array}{l}55 \\
(50-65)\end{array}$ & $\begin{array}{l}55^{*} \\
(50-66)\end{array}$ & $\begin{array}{l}54.5 \\
(50-65)\end{array}$ & $\begin{array}{l}54.5 \\
(50-65.3)\end{array}$ & $\begin{array}{l}55 \\
(50-68)\end{array}$ & $\begin{array}{l}55^{*} \\
(54-69)\end{array}$ & $\begin{array}{l}54 \\
(50-63)\end{array}$ & $\begin{array}{l}55 \\
(50-65)\end{array}$ \\
\hline Aggressive behavior & $\begin{array}{l}58 \\
(52-64)\end{array}$ & $\begin{array}{l}61 * * \\
(52-66)\end{array}$ & $\begin{array}{l}57 \\
(51-64)\end{array}$ & $\begin{array}{l}60 * * \\
(52-64.3)\end{array}$ & $\begin{array}{l}59 \\
(54-68)\end{array}$ & $\begin{array}{l}61.5^{* *} \\
(56-70)\end{array}$ & $\begin{array}{l}57 \\
(52-64)\end{array}$ & $\begin{array}{l}61 * * \\
(53.5-66)\end{array}$ \\
\hline
\end{tabular}

$A S D$ autism spectrum disorder, $A D H D$ attention-deficit hyperactivity disorder, $I D$ intellectual disorder, $N D D$ neurodevelopmental disorder All numbers displayed within the table are displayed as median (IQR)

$* \mathrm{p}<0.05, * * \mathrm{p}<0.01$

elevated T-scores on the total problem scale, externalizing scale, and each syndrome scale of thought problems, delinquent behavior, and aggressive behavior. Finally, patients with ID had significantly elevated scores on the total problem scale, externalizing scale, each syndrome scale of anxiety/depression and aggressive behavior. The longitudinal T-score changes before and after school closure with statistically significant differences are shown in Fig. 2 and Supplementary Figs S1-S4.

\section{Discussion}

It has been reported that prolonged periods of social isolation and loneliness due to infectious disease outbreaks lead to anxiety, depression, and trauma (Loades et al., 2020). Similarly, increased anxiety and depression have been reported in COVID-19 outbreaks (Tang et al., 2021; Xie et al., 2020; Yeasmin et al., 2020; Zhou et al., 2020). Furthermore, behavioral and emotional responses to social isolation and loneliness due to school closures differed between children with typical development and children with ASD and ADHD. Generally, children with NDDs are more vulnerable to uncertain situations, such as COVID-19, because they have an intolerance to uncertainty and unfriendly environments that inhibit their regular routine and have difficulties following instructions and understanding the complexity of the pandemic. However, few studies exist that investigate how school closures impact children with NDDs. To the best of our knowledge, this is the first study exploring emotional and behavioral changes during school closures due to COVID-19 in a Japanese pediatric population with NDDs using the CBCL. The findings showed that only children with ID showed a significant increase in anxiety and depression. Moreover, we found that the total problem scale, externalizing scale, and aggressive behavior scale were elevated in all NDDs, regardless of the type of diagnosis.

Augmentation of externalizing behavior due to increased aggressive behavior and an increase in thought problems were found in children with ASD, while, contrary to previous studies, anxiety and depression remained unchanged. Several factors may have caused these differences in emotions and behaviors. First, children with ASD have different perceptions of the COVID-19 pandemic and school closures. 
A
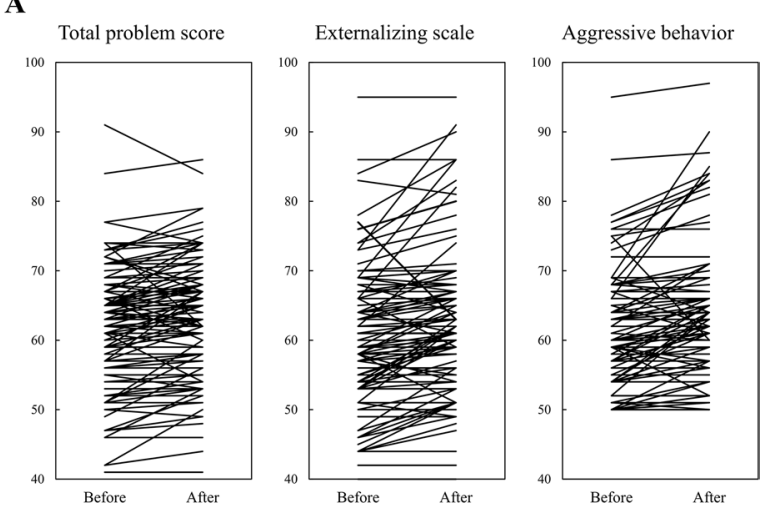

B
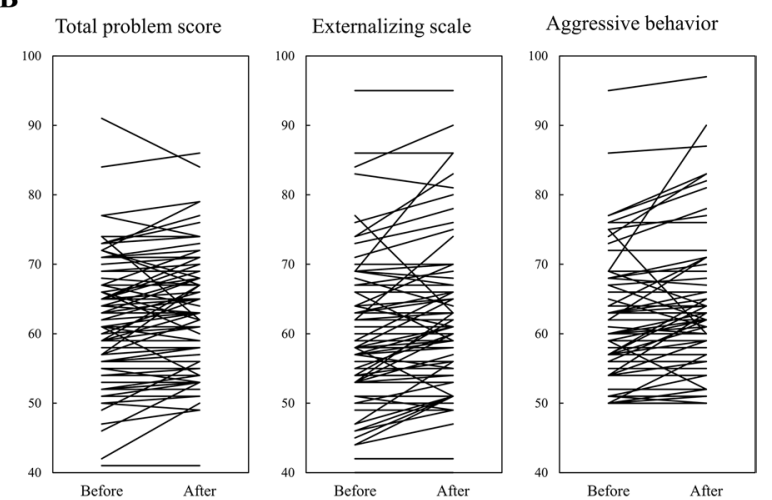

C
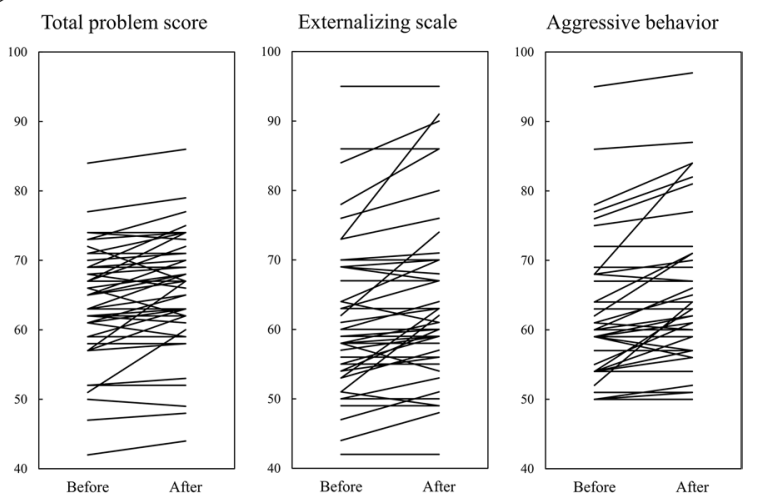

D
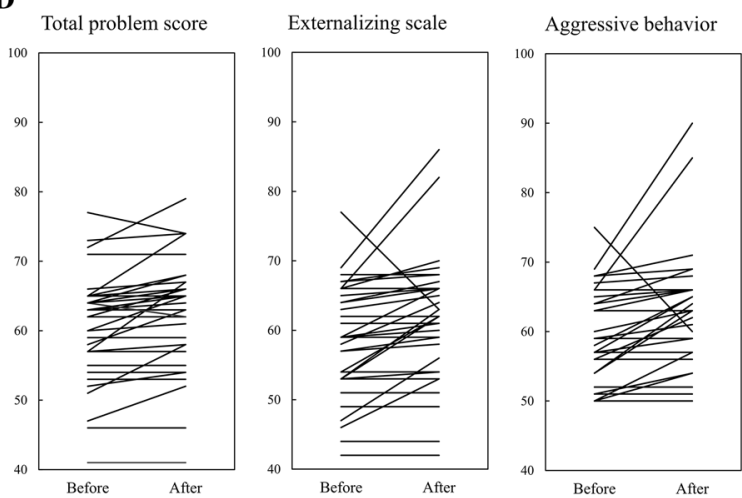

Fig. 2 The longitudinal T-score changes before and after school closure of total problem, externalizing scale, aggressive behavior. A All subjects, $B$ Subjects with ASD, $C$ Subjects with ADHD, and $D$ Subjects with ID

That is, they have difficulty adapting to the changing environment and become agitated and exasperated when anything is rearranged or shifted from its existing setup (Singh et al., 2020). Second, they have different ways of expressing anxiety. Evans et al. (2005) investigated children's fears and behavioral problems and reported that children with ASD expressed their anxiety and fear through externalizing behaviors. In addition, Kanne and Mazurek (2011) reported that $68 \%$ of parents of children with ASD reported that their children had engaged in aggressive behaviors.

Children with ADHD showed a significant increase in externalizing behavior due to increased delinquent and aggressive behavior and an increase in thought problems. Retz et al. (2020) pointed out that children with ADHD are prone to comorbid oppositional defiant disorder and conduct disorder, which are associated with aggressive and delinquent behaviors. In addition, it was reported that there was an association between anxiety disorders and externalizing disorders in children with ADHD, and that young children with ADHD were unable to express their anxiety directly, so they engaged in externalizing behaviors that were contradictory to anxiety behaviors (Marmorstein, 2007). Moreover, it is difficult for them to remain confined to a place during lockdown or school closures and not touch things that might infect them during COVID-19. Therefore, these situations are more stressful for them compared with children with typical development. Zhang et al. (2020) also reported that the COVID-19 outbreak is associated with an exacerbation of ADHD symptoms, especially anger frequency, and suggests that an appropriate approach is needed. The results of this study supported the above suggestion.

Overall, the scales showed changes in statistical significance, with most patients showing small changes, and a small number of patients showing a marked change (Fig. 2). That is, while school closures had a limited impact on many patients, it had a strong impact on others, causing behavioral and emotional deterioration. Lee (2020) pointed out that social distancing measures can result in social isolation in an abusive home, with abuse likely exacerbated during this time of economic uncertainty and stress. Reports of child abuse, neglect, exploitation, and domestic violence were rising exponentially during the COVID-19 pandemic and lockdown (UNICEF). Furthermore, children with NDDs are more likely to be abused (Govindshenoy \& Spencer, 2007) and aggravating behavioral problems make them more prone to this abuse. Thus, in situations such as COVID-19 and school closures, it is important to provide appropriate support, while considering that children with NDDs may experience behavioral deterioration.

Although the findings of this study provided important insights, several limitations should be considered when interpreting these. First, there was no control group; thus, no comparison was made with children with typical 
development in the same condition. Second, although the CBCL was originally designed to be answered in retrospect (over the past six months), respondents were asked to answer simultaneously for two weeks before and after school closures in this study. Two weeks before and after school closure was quite short and changes at the beginning may have been different from changes in the long term. Data on behavioral and emotional issues before and after school closure were collected at the same; therefore, the data may have been inaccurate due to recall bias. It is also possible that parents and children spent more time together after school closures; thus, behavioral problems became more of a concern than before.

In conclusion, the impact of school closures due to COVID-19 on children with NDDs was manifested as an increase in externalizing behavior due to increased aggressive behavior. These findings suggested that it is necessary to provide appropriate support that considers the behavioral characteristics of each individual in pandemic and similar situations. It is important to clarify the prospect such as the period of school closure to spend a stable life with peace of mind during an outbreak for children with NDDs. It was also suggested that there is a need to increase support for NDD children and their families in pandemics and similar situations. Furthermore, these findings can provide the foundation for future researchers to further investigate other factors related to COVID-19 and their impact on children with NDDs.

Supplementary Information The online version contains supplementary material available at https://doi.org/10.1007/s10803-021-05119-0.

Acknowledgments We would like to thank patients and their families who cooperated in this study.

Authors Contribution Conceptualization: Shinji Saitoh and Kei Ohashi; Collection and analysis of data: Kei Ohashi and Naomi Kawaoka; Provided clinical information: Masayuki Imaeda, Tomoko Asai, Taishi Miyachi, Satomi Fukuhara, and Kei Ohashi; Provided advice: Kei Ohashi; Writing-original draft preparation: Kei Ohashi and Naomi Kawaoka.

Funding The authors did not receive support from any organization for the submitted work.

\section{Declarations}

Conflict of Interest The authors have no relevant financial or non-financial interests to disclose.

Ethical Approval Ethics approval was obtained from the ethics committee of Nagoya City University Medical School (No. 60-20-0018). The procedures used in this study adhere to the tenets of the Declaration of Helsinki.
Consent to Participate The living environment questionnaire also served as a consent form for the study, and consent was deemed to have been obtained when the completed questionnaires were mailed.

Consent to Publish The participant has consented to the submission to the journal.

\section{References}

Achenbach, T. M. (1991). Manual for the child behavior checklist/4-18 and 1991 Profile. University of Vermont, Department of Psychiatry.

American Psychiatric Association (2013). Diagnostic and statistical manual of mental disorders (fifth edn. (DSM-5)). Washington DC: American Psychiatric Publishing

Evans, D. W., Canavera, K., Kleinpeter, F. L., Maccubbin, E., \& Taga, K. (2005). The fears, phobias and anxieties of children with autism spectrum disorders and Down syndrome: Comparisons with developmentally and chronologically age matched children. Child Psychiatry \& Human Development, 36(1), 3-26.

Govindshenoy, M., \& Spencer, N. (2007). Abuse of the disabled child: A systematic review of population-based studies. Child Care, Health \& Development, 33(5), 552-558.

Jiao, W. Y., Wang, L. N., Liu, J., Fang, S. F., Jiao, F. Y., PettoelloMantovani, M., \& Somekh, E. (2020). Behavioral and emotional disorders in children during the COVID-19 Epidemic. Journal of Pediatrics, 221, 264-266.e1.

Kanda, Y. (2013). Investigation of the freely available easy-to-use software "EZR" for medical statistics. Bone Marrow Transplantation, 48(3), 452-458.

Kanne, S. M., \& Mazurek, M. O. (2011). Aggression in children and adolescents with ASD: Prevalence and risk factors. Journal of Autism \& Developmental Disorders, 41(7), 926-937.

Lee, J. (2020). Mental health effects of school closures during COVID19. Lancet Child Adolescent Health, 4(6), 421.

Loades, M. E., Chatburn, E., Higson-Sweeney, N., Reynolds, S., Shafran, R., Brigden, A., et al. (2020). Rapid systematic review: The impact of social isolation and loneliness on the mental health of children and adolescents in the context of COVID-19. Journal of the American Academy of Child \& Adolescent Psychiatry, 59(11), 1218-1239.e3.

Marmorstein, N. R. (2007). Relationships between anxiety and externalizing disorders in youth: The influences of age and gender. Journal of Anxiety Disorders, 21(3), 420-432.

Retz, W., Ginsberg, Y., Turner, D., Barra, S., Retz-Junginger, P., Larsson, H., \& Asherson, P. (2020). Attention-Deficit/Hyperactivity Disorder (ADHD), antisociality and delinquent behavior over the lifespan. Neuroscience \& Biobehavioral Reviews, 120, 236-248.

Singh, S., Roy, D., Sinha, K., Parveen, S., Sharma, G., \& Joshi, G. (2020). Impact of COVID-19 and lockdown on mental health of children and adolescents A narrative review with recommendations. Psychiatry Research, 293, 113429.

Tang, S., Xiang, M., Cheung, T., \& Xiang, Y. T. (2021). Mental health and its correlates among children and adolescents during COVID19 School Closure: The importance of parent-child discussion. Journal of Affective Disorders, 279, 353-360.

UNICEF.org [homepage on the internet]. COVID-19: Children at heightened risk of abuse, neglect, exploitation and violence amidst intensifying containment measures; Accessed 13 January, 2021. Available from: https://www.unicef.org/press-releases/covid-19children-heightened-risk-abuse-neglect-exploitation-and-viole nce-amidst. 
Xie, X., Xue, Q., Zhou, Y., Zhu, K., Liu, Q., Zhang, J., \& Song, R. (2020). Mental health status among children in home confinement during the coronavirus disease 2019 outbreak in Hubei Province China. JAMA Pediatrics, 174(9), 898-900.

Yeasmin, S., Banik, R., Hossain, S., Hossain, M. N., Mahumud, R., Salma, N., \& Hossain, M. M. (2020). Impact of COVID-19 pandemic on the mental health of children in Bangladesh: A crosssectional study. Children \& Youth Services Review, 117, 105277.

Zhang, J., Shuai, L., Yu, H., Wang, Z., Qiu, M., Lu, L., et al. (2020). Acute stress, behavioural symptoms and mood states among school-age children with attention-deficit/hyperactive disorder during the COVID-19 outbreak. Asian Journal of Psychiatry, 51, 102077.
Zhou, S. J., Zhang, L. G., Wang, L. L., Guo, Z. C., Wang, J. Q., Chen, J. C., et al. (2020). Prevalence and socio-demographic correlates of psychological health problems in Chinese adolescents during the outbreak of COVID-19. European Child \& Adolescent Psychiatry, 29(6), 749-758.

Publisher's Note Springer Nature remains neutral with regard to jurisdictional claims in published maps and institutional affiliations. 